\title{
O processo de reelaboração do fazer pedagógico de uma professora de inglês: construindo um ensino que faz sentido ${ }^{1}$
}

\author{
Valdeni da Silva Reis \\ Faculdade Interdisciplinar em Humanidade da Universidade Federal dos Vales do Jequitinhonha e Mucuri, \\ Cabral Contagem, MG - Brasil. \\ valdeni.reis@gmail.com
}

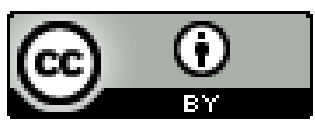

Educação: teoria e prática, Rio Claro, SP, Brasil - elSSN: 1981-8106

Está licenciada sob Licença Creative Common

\section{Resumo}

Muito comumente, a prática pedagógica do professor de língua estrangeira está baseada em ensinar estruturas isoladas e, deste modo, a atenção dos alunos é direcionada apenas para aspectos formais da língua (WILLIAMS, 2001). Isso acaba por gerar uma aula descontextualizada na qual o professor é o centro de sua prática pedagógica e uma série de atividades é proposta de forma "mecânica" sem que sejam criadas possibilidades para que a aprendizagem dos alunos se desenvolva de fato. $\mathrm{O}$ objetivo central deste artigo é investigar as possibilidades de outro fazer pedagógico fundamentado na comunicação de forma significativa, fomentando a aprendizagem. Para tanto, são discutidos conceitos teóricos referentes ao insumo e produção (input/output); ao foco nas formas e foco na forma (FonF); ao ensino significativo e às representações no ensino-aprendizagem de LE. Nesse sentido, são apresentados e discutidos dados de uma pesquisa-ação colaborativa que emerge a partir do desejo de uma professora de inglês de descobrir uma nova possibilidade para seu fazer pedagógico.

Palavras-Chave: Prática pedagógica. Ensino de língua estrangeira. Ensino de gramática. Ensino significativo.

\section{The process of redesigning the pedagogical practice of an English teacher: formulating a teaching practice that makes sense}

\begin{abstract}
\footnotetext{
${ }^{1}$ Agradeço à professora Maria Clara e ao aluno da graduação Carlos Eduardo (nomes fictícios) participantes da pesquisa maior da qual o presente trabalho é também originado, conforme relatório de pesquisa. (ver REIS, DAMASCENO e MAIA. Disponível em http://www.letras.ufmg.br/arado/pesqsala.pdf). Acesso em o4/04/2012 às $23 \mathrm{~h} 30 \mathrm{~min}$.
}

[Escolha a data] 
Very commonly the practice of a foreign language teacher is based on isolated structures, thus directing students' attention only to formal aspects of the language (WILLIAMS, 2001). This fact generates a decontextualized lesson where the teacher is the center of his/her practice and a series of activities is proposed in a "mechanical" way without creating real possibilities to develop students' learning. The central aim of this paper is to investigate other possibilities of pedagogical practice grounded in meaningful communication, which fosters learning. In order to do so, theoretical concepts concerning the input and output; the focus on the forms and focus on form (FonF); teaching under a meaningful perspective and the teaching and learning of a foreign language representations are discussed. Accordingly, data from a collaborative action research that emerges from the desire of an English teacher to discover a new possibility for her pedagogical practice is presented and discussed.

Keywords: Teaching practice. Foreign language teaching. Grammar teaching. Meaningful teaching

\section{Introdução}

Podemos dizer, com certa tranquilidade, que muitas são as inquietações que permeiam a prática pedagógica de um professor de língua estrangeira - doravante LE. Dentre essas inquietações citamos, por exemplo, o bombardeamento teórico ao qual estamos submetidos ao longo de nossa formação; o embate dessas teorias com a nossa prática e todos os conflitos daí oriundos e as tantas realidades vivenciadas em nossas salas de aulas (número de alunos, falta de recursos pedagógicos, as demandas dos alunos segundo a realidade de cada um, para citar apenas alguns). Contudo, acreditamos que uma das principais inquietações que insistem em acompanhar o professor de uma LE é aquela referente ao ensino da gramática. Deste modo, nossa proposta central para esse artigo é discutir como e se é possível trabalhar o ensino de gramática de forma significativa. Para tanto, lançamos mão de conceitos relacionados à instrução formal na prática pedagógica de LE.

De um modo bem abrangente, o termo instrução formal refere-se ao ensino de qualquer aspecto da língua - incluindo aí o ensino de gramática - em ambiente ou em situação formal de ensino que normalmente se desenrola dentro da sala de aula. De acordo com Ellis (1994), essa definição reflete tanto a importância tradicionalmente dada ao ensino de gramática na pedagogia da linguagem, quanto à centralidade ocupada por ela e por seu ensino nas pesquisas relativas à aquisição de LE. Esse foco, prossegue o autor, garante a motivação dos professores, pois os auxilia numa melhor compreensão acerca dos fatores que determinam o sucesso ou insucesso de uma instrução, ou de um determinado aspecto do ensino. O foco na instrução formal também tem motivado alguns pesquisadores 
(SCHIMIDT, 2001; ELLIS, 2001; MELLO; DUTRA, 2000; GONTIJO, 2004; LONG; ROBINSON, 1998; entre outros), pois colabora para a exploração de aspectos importantes às teorias relativas ao ensino-aprendizagem de línguas, em especial ao que se refere à "relação entre o ambiente linguístico e os mecanismos internos de processamento do aprendiz" (ELLIS, 1994, p.611).

Assim, a instrução formal e todas as suas implicações colaboram para o desenvolvimento das discussões acerca do ensino e da aprendizagem, tanto no que se refere à prática do professor, quanto às teorias. Devemos, contudo, sugerir para a presente discussão, a união da prática e da teoria; concomitantemente, propondo a união do professor e pesquisador.

Acreditamos que o pesquisador não pode se eximir de sua condição de sujeito socialmente atuante em sua realidade. O professor, nessa relação, deve se colocar ativo em suas circunstâncias e experiências para o desenvolvimento de ações voltadas para a melhoria de seu trabalho pedagógico em sala de aula, transformando-se, assim, em investigador de sua própria prática (DUTRA, 2004; MATEUS, 2002).

A fim de discutir a relação entre teoria e prática e pesquisador-professor, apresentamos alguns dados de uma pesquisa desenvolvida a partir das necessidades e inquietações referentes ao ensino da gramática de Maria Clara ${ }^{2}$, professora da rede municipal de ensino da cidade de Betim/MG.

Devemos salientar que durante o percurso dessa pesquisa houve o desejo de que todos os passos fossem dados com a professora e nunca para a professora, no intuito de que Ihe fossem oferecidos instrumentos para investigar e estudar sua prática pedagógica produzindo, com isso, conhecimento (TELLES, 2002) sobre seu próprio fazer e sobre as possibilidades para transformá-lo.

O presente trabalho objetiva, então, investigar como a professora Maria Clara concebe o ensino nos limites da sala de aula, apresentando e discutindo os caminhos percorridos por ela rumo a um ensino mais significativo ${ }^{3}$. Para tanto, torna-se necessária uma reestruturação de sua visão de ensino da gramática, (des)construindo, assim, conceitos referentes à instrução formal e se aproximando, por fim, do foco na forma ${ }^{4}$ (FonF) como

\footnotetext{
${ }^{2}$ Nome fictício escolhido pela própria professora.

${ }^{3}$ Esse conceito será detalhado no decorrer do trabalho.

${ }^{4}$ Conceito discutido na seção que se segue. 
uma possibilidade para alcançar um modo de ensinar mais contextualizado, logo, mais atraente e mais efetivo.

2 A instrução formal em dois focos:

Apesar de encontrarmos diferentes tipos de instrução formal ${ }^{5}$, nossa discussão está centrada apenas em dois tipos principais, a saber, o foco nas formas e foco na forma (FonF) (SCHIMIDT, 2001; ELLIS, 2001; 1994; MELLO; DUTRA, 2000; GONTIJO, 2004; LONG; ROBINSON, 1998).

De acordo com Ellis (1994), foco nas formas concerne à instrução centrada no isolamento de formas linguísticas não apenas para o ensino, mas também para a avaliação acerca da aprendizagem de tais estruturas. De modo que o foco nas formas está ligado à apresentação de estruturas em uma espécie de análise linguística. Essas estruturas se referem a itens que são sequenciados para serem apresentados aos alunos de maneira aditiva, segundo um currículo estrutural de modelos lineares de acordo com o grau de dificuldade (LONG; ROBINSON, 1998). Isso acontece, por exemplo, quando há o foco isolado em conteúdos como presente simples ou passado, uso dos fonemas ou a entonação, entre outras possibilidades.

Essa abordagem pressupõe, então, que a aprendizagem da linguagem aconteça de modo segmentado, logo, sequencial. Ao mesmo tempo, essa vertente prevê uma linearidade no ensino de LE. Tal linearidade pode, ainda, ser vislumbrada ao encontrarmos na prática de alguns professores (ou na nossa própria), a crença de que primeiro devemos ensinar/aprender o verbo to be, depois o present continuous tense depois o simple present e, antes de tudo isso, os personal pronouns e assim por diante. Nessa perspectiva, o ensino de língua é trabalhado de modo fragmentado e o foco está nas formas linguísticas isoladas e descontextualizadas.

Em direção contrária, insurgem pesquisas e discussões no campo da Linguística Aplicada - doravante LA - que apontam para outro fazer. Emerge, assim, a discussão sobre uma prática que priorize a necessidade de solucionar problemas durante a aprendizagem de um dado tópico; desenvolvendo habilidades específicas e /ou oferecendo um ensino de modo mais contextualizado, focando a atenção do aprendiz em pontos específicos que

\footnotetext{
${ }^{5}$ Ver Ellis 1994.

Educação: Teoria e Prática/ Rio Claro/ Vol. 23, n.42/ p. 106-126/ Jan-Abr. 2013.
} 
surgem durante a solução de problemas ou execução de tarefas a serem apreendidos de modo comunicativo ${ }^{6}$ (ELLIS, 1994).

Nessa perspectiva há alternância entre foco no significado e na forma, de modo que a atenção do aprendiz seja focada em determinadas propriedades ou estruturas linguísticas durante a execução de tarefas ou performance em atividades comunicativas (ELLIS, 1994, p.639). Atividades comunicativas são aqui compreendidas como aquelas voltadas para a emissão de mensagens contextualizadas, trazendo, para dentro da sala de aula, elementos que possibilitem ao aluno opinar, tomar decisões, produzir e construir conhecimento na língua estrangeira (ALMEIDA FILHO, 2005), quando convocado a usar a língua em situações da vida real.

Desmembrando o conceito foco na forma, Williams (2001) afirma que a palavra foco, ponto central do termo, refere-se ao processo de aprendizagem no qual a atenção do aprendiz é envolvida. Já a palavra forma se refere à estrutura linguística na qual a atenção será focada.

Ainda que a abordagem do foco na forma seja amplamente difundida nos domínios da LA, o fazer dos professores, muitas vezes, caminha em outra direção, sendo esta, a do foco nas formas. Conforme Dutra (2004, p.20), “o conhecimento de procedimentos instrucionais não nos leva, necessariamente, a uma prática eficiente ou consciente", a autora, citando Borg (1998), afirma que atualmente é crescente o interesse "em estudar por que e como muitos professores recorrem ao ensino de aspectos estruturais da língua" (BORG, 1998, apud DUTRA, 2004, p. 20). Nossa hipótese é de que o simples conhecimento de todas as teorias que orientam o professor para que este possa modificar positivamente seu fazer tornam-se insuficientes, uma vez que entendemos que essa reprodução está atrelada às representações ${ }^{7}$ que cada um carrega consigo.

Assim, defendemos que as discussões e pesquisas sobre o fazer do professor sejam capazes de criar possibilidades de escuta do professor para daí investigar/descobrir os princípios e as representações que delimitam sua prática pedagógica. Essas representações

\footnotetext{
${ }^{6}$ Segundo Almeida Filho (1993, p.47) o ensino comunicativo é aquele que "organiza as experiências de aprender em termos de atividades/tarefas de real interesse e/ou necessidade do aluno para que ele se capacite a usar a língua alvo para realizar ações de verdade na interação com outros falantes-usuários dessa língua".

${ }^{7}$ Retomaremos esse conceito a seguir. 
moldam os significados atribuídos aos papéis desempenhados pelos envolvidos nesse processo de ensino-aprendizagem de LE, bem como o significado de sua prática.

A noção de representações, aqui evocada, baseia-se no sentido das Formações Imaginárias, noção desenvolvida nos trabalhos da primeira e da segunda fase de Pêcheux (PÊCHEUX, 1995; PÊCHEUX; FUCHS, 1997). Segundo Coracini (2003, p. 219), "toda representação se constrói a partir das experiências pessoais, mas não apenas: elas se constroem a partir das experiências dos outros, daqueles que nos cercam e que nos levam a crer nisto ou naquilo, que nos dizem quem somos". Segundo Pêcheux (1995), o que funciona no discurso é uma série de formações imaginárias - as representações - designadas a partir das posições que professor e aluno atribuem a si e aos outros, ou "a imagem que cada um tem, sobre sua própria posição e sobre as posições dos outros" (Pêcheux, 1995, p. 85). De acordo com Pêcheux (1995) as representações são projeções que resultam sempre de processos discursivos ${ }^{8}$ anteriores.

Desse modo, procuramos identificar, a seguir, as representações e concepções acerca do ensino de gramática da professora Maria Clara por meio da observação de sua aula e de uma entrevista (anexo 1$)^{9}$, para, a partir daí, propor novas possibilidades de reorganização pedagógica.

\section{Uma aula de estruturas: o foco é(ra) nas formas}

Na primeira aula observada ${ }^{10}$, a professora Maria Clara inicia sua aula da seguinte maneira: "Bom dia. Olha, existe no inglês uma forma que se chama present continuous tense...". De forma isolada e descontextualizada, a professora, em sua instrução, foca a estrutura verbal desse tempo da língua inglesa. Essa sua ação nos leva a inferir que sua concepção de ensino gramatical está focada nas formas isoladas de estruturas linguísticas da língua inglesa, não havendo distinção entre tempo verbal e aspecto linguístico. A professora prossegue, escrevendo no quadro outras estruturas (personal pronouns e verb to be), para

\footnotetext{
${ }^{8}$ Segundo Orlandi (1999) o processo discursivo se configura no que é linguístico-histórica, que não se restringe a regras, mas sim, às suas condições de produção em relação à memória, lugar onde a ideologia, o inconsciente, o esquecimento, a falha, o equívoco, residem, revelando seu funcionamento no discurso.

${ }^{9}$ Ver em anexo 1 as perguntas que orientaram essa entrevista.

${ }^{10}$ Descrevemos, posteriormente, todo o contexto bem como todas as etapas dessa pesquisa na seção sobre metodologia.
} 
que somente a partir daí acontecesse a explicação proposta. Em seguida, a professora propõe aos alunos uma série de atividades de repetição $\left(d r i l l s^{11}\right)$ e finaliza a aula.

Observando o plano dessa aula de Maria Clara (anexo 2), podemos perceber o modo fragmentado de sua visão de ensino de língua. A professora inicia sua explicação/aula nomeando a forma gramatical a ser abordada naquele dia. O foco é nas formas, como podemos observar em seu plano de aula (anexo 2): "tópico: what are you doing? Rever personal pronouns. Explicar sobre o acréscimo do ING. / Estrutura do present continuous tense" (grifo nosso). Maria Clara aponta em seu plano o uso de figuras/imagens, contudo nem ao menos as cita durante a aula.

Na sequência, a professora propõe “explicar formas afirmativa/negativa/ interrogativa" e encerra a aula com exercícios de acordo com o modelo exposto no quadro. Alguns alunos tentam fazer o exercício e pedem a ajuda da professora, outros caminham pela sala e muitos conversam. $O$ sinal bate, sem a conclusão da atividade que ficou como tarefa de casa.

A instrução formal dessa aula está baseada em estruturas isoladas. Assim, a atenção dos alunos é direcionada para aspectos formais da língua, resultando em uma aula descontextualizada e centrada na professora. Não são criadas possibilidades para que o insumo (input) fosse devidamente processado, possibilitando a emergência da produção por parte dos alunos e favorecendo, com isso, sua aprendizagem. De acordo com Ellis (1994), a aquisição de LE pode ser desenvolvida somente se o aluno tiver acesso ao insumo, na forma escrita ou falada. Entretanto, esse insumo deve ser apresentado aos alunos de maneira compreensível conforme pontua Swain $(1985$, p. 245$)$ na passagem abaixo:

O insumo compreensível significa para mim a língua sendo dirigida ao aprendiz contendo algum novo elemento, mas que, no entanto, é entendida pelo aluno devido a elementos - pistas, linguísticas ou extralinguísticas; situacionais, ou ainda, pelo conhecimento de mundo do aluno.

Os excertos apresentados acima, bem como a aula observada, indicam que o insumo oferecido aos alunos não foi compreensível, nem tampouco significativo, não favorecendo, segundo acreditamos, que o conteúdo fosse apreendido pelos alunos. Significativa, segundo Paiva e Figueiredo (2005, p.175), é uma abordagem que leve em consideração o universo

\footnotetext{
${ }^{11}$ No âmbito do ensino de LE esse termo significa um ensino cujas técnicas são extensivamente focadas na repetição. Os alunos podem, por exemplo, repetir exaustivamente palavras ou expressões, para trabalhar uma determinada estrutura ou pronúncia, individualmente, em pares ou em grupo.
} 
dos alunos "fazendo com que os alunos produzam língua, em vez de somente reproduzi-las", utilizando a língua de forma contextualizada, podendo partir da vivência, logo da experiência dos alunos.

Observando a fala da professora, fica ainda mais evidente sua posição frente às representações acerca do ensino de gramática que conduzem seu fazer. Vejamos o seguinte excerto:

P: (...) não acho que a gramática seje/ seja principal// não/ embora/ que/ ah.../ a aula com a gramática/ é uma aula mais tranquila, né?// eu/ assim/ o dia que é pra eu ensinar gramática/ que cê vai lá/ põe as regras no quadro// a aula é um silêncio total mas ninguém fala nada mas também eu acho que ninguém aprende muita coisa não// (.... $)^{12}$ (grifo nosso)

Segundo o relato acima, podemos indicar que nas representações de Maria Clara ensinar gramática significa colocar regras no quadro e algo que deixa a aula mais tranquila, mais cômoda, uma vez que os alunos deverão se preocupar em apenas copiar uma série de regras que ocupará muitas folhas de seus cadernos. Por outro lado, o ensino de gramática fica restrito a essas páginas e fadado a não alcançar um lugar na aprendizagem dos alunos. $A$ professora, contudo, não ignora esse fato como podemos observar pelos trechos de sua fala: "a aula é um silêncio total, mas ninguém fala nada, mas também eu acho que ninguém aprende muita coisa não". E ela tem razão, seus alunos não aprendem mesmo, uma vez que as estruturas da LE vistas isoladamente não fazem sentido para seus alunos. Essa ideia é fortemente expressada no excerto abaixo:

P: ... porque, se eu tivesse chegado, enchido o quadro de gramática/ é// coloque no no/ no passado/ volta pro presente/ é/ passe para o plural/ aquelas listas/ (...) (grifo nosso)

Formas, estruturas e isolamento do conteúdo em regras gramaticais. Essa é a representação de ensino de gramática que Maria Clara possui em seu discurso: "coloque no no/ no passado/ volta pro presente/ é/ passe para o plural/ aquelas listas/", mas que sobretudo, direciona sua prática: "explicar formas afirmativa/ negativa/ interrogativa" (Grifo nosso) (ver plano). Essa representação configura, então, o formato da instrução formal por ela desenvolvida, calcada no foco nas formas, isolando a comunicação, o significado e a necessidade de fazer sentido para os alunos.

\footnotetext{
${ }^{12}$ Os símbolos de transcrição são os seguintes: $\mathrm{P}$ = professora; $\mathrm{A}=$ Aluno; / = pausa breve; // pausa longa; [ ] = comentários da pesquisadora; $((X X X))=$ sequência incompreensível; $(\ldots)=$ omissão de trechos da fala; $X=$ suspensão de um nome próprio.
} 
A seguir descrevemos, brevemente, o contexto, participantes e metodologia da presente investigação.

\section{Percurso metodológico: contexto e participantes}

A presente pesquisa é de base qualitativa e interpretativista. Larsen-Freeman e Long (1991) definem metodologia qualitativa como aquela que apresenta um estudo do sentido social de um dado aspecto em contextos particulares - no caso, a sala de aula - nos quais os pesquisadores observam e analisam os dados ao invés de testar hipóteses. O foco é no professor, no intuito de investigar sua prática e, consequentemente, como a instrução por ele dirigida interfere na aprendizagem de seus alunos.

A pesquisa se desenrola no contexto de uma escola municipal localizada na área rural da cidade de Betim / MG. A turma observada tem vinte e cinco alunos matriculados, mas apenas dezessete são frequentes. Os alunos têm idade entre treze e quatorze anos e cursam o 2 음 ano do 3으 ciclo (equivalente à 7ạ série do 1으 grau do ensino fundamental).

Reuniões semanais foram realizadas entre a professora regente, um aluno da graduação do curso de Letras $^{13}$ e a pesquisadora, para discussão de textos e para o planejamento em conjunto de atividades significativas. No final de cada aula observada, havia uma discussão entre os participantes acerca das atividades desenvolvidas; a reação dos alunos; as impressões da professora e da ação colaborativa como um todo.

A pesquisa, aqui relatada, se refere, como pode ser apontado, a uma pesquisa-ação colaborativa. Nunan (1992) define pesquisa-ação como um estudo de caso escolar, feita por professores que usam o status de participantes como base para desenvolver habilidades de observação e análise da prática docente. O processo dessa pesquisa pode ser compreendido como uma busca pela compreensão mais elaborada de perguntas e/ou problemas previamente identificados, envolvendo monitoramento e avaliação daquilo que é implementado. Esse tipo de pesquisa é sempre conduzido por professores que desejam fazer algo para aprimorar sua própria prática.

Em seu primeiro contato com os pesquisadores, a professora demonstrou interesse em promover o ensino de gramática, que ela denominava de mais atraente, uma vez que, segundo Maria Clara, seus alunos mostravam-se sempre indiferentes às atividades propostas

\footnotetext{
${ }^{13}$ Aluno que também colaborava com a pesquisa. Não se trata de estágio supervisionado, mas o aluno era inscrito em uma disciplina que previa a pesquisa em salas de aula da língua inglesa.
} 
dentro da sala de aula. Desse modo, a professora defendeu seu desejo de trabalhar o ensino da gramática para que a motivação dos alunos fosse alcançada. Ponto de partida para as ações implementadas foi a tese de que, por meio de um ensino mais contextualizado, os alunos ficariam mais motivados para desenvolver sua aprendizagem, construindo, enfim, um sentido naquilo a ser ensinado.

Os dados reportados a seguir referem-se às atividades desenvolvidas pela professora para que seja evidenciada a reestruturação da instrução formal por ela dispensada durante suas aulas de língua inglesa. Outros dados coletados, que ainda serão apresentados, compreendem trechos de entrevistas realizadas em dois momentos distintos ${ }^{14} \mathrm{com}^{\mathrm{a}}$ professora Maria Clara e diários escritos por ela durante todo o processo.

\section{Focando a instrução formal na forma: a trajetória de uma aula significativa}

Logo após a observação da aula acima descrita, a professora foi questionada da seguinte forma: por que não falar em inglês na sala de aula?, isso porque nenhuma palavra na língua alvo foi usada durante a aula de 50 minutos. Diante desse questionamento, Maria Clara refletiu sobre o uso da LE dentro do contexto da sala de aula e propôs outro direcionamento para pequenos detalhes de sua prática: daquele momento em diante o inglês deveria ser mais utilizado dentro da sala, a partir de construções básicas para a comunicação cotidiana.

Na aula seguinte, a professora inicia a aula cumprimentando seus alunos na língua alvo do seguinte modo: good morning. Em seguida, Maria Clara incentiva que estes respondam da mesma forma. A professora prossegue: “I am fine, How are you?" E conduz os alunos para que eles respondam em inglês. A partir daí a professora usa o contexto da sala de aula para ensinar aos alunos expressões que deveriam ser utilizadas dentro da sala a partir daquele dia, como por exemplo: "Eduardo, close the door, please", "open your notebooks", "thanks" etc. A professora usava a língua alvo, privilegiando a comunicação de forma significativa. Vejamos, abaixo, no diário de Maria Clara, como a primeira observação por parte da pesquisadora afetou o direcionamento de sua aula seguinte naquela mesma turma.

\footnotetext{
${ }^{14}$ O primeiro momento foi logo no início da pesquisa e antes das primeiras discussões; já o segundo momento foi ao final da pesquisa.
} 
Depois da observação de minha aula na turma de 2 o ano do 3 o ciclo ... a X (questionou ou comentou) alguns pontos que poderiam estar sendo melhorados durante as minhas aulas de LI. Ela disse que eu deveria usar mais inglês em frases simples, comando, para que os alunos tivessem um contato maior com a língua. Então, na aula seguinte, eu sugeri aos alunos que a partir daquela aula nós usaríamos algumas expressões durante as aulas de LI. Fui criando situações e escrevendo no quadro as "expressions", como: close the door, open the door... até somar 15 expressões. Cada aluno ficou responsável por escrever sua expressão de forma bem colorida para fixar no mural, que fizemos na sala [conforme figura abaixo]. Senti que a partir deste dia a maioria dos alunos que encontravam comigo sempre falava alguma expressão em inglês. Achei válida a experiência e estendi a idéia em todas as outras turmas. Tem sido muito gratificante e os alunos demonstraram um entusiasmo a mais. Alguns, é claro, ainda estão inibidos, mas em geral houve um aquecimento na sala. Esta foi a primeira experiência que surtiu um efeito positivo na sala 5 , pois é uma turma bastante apática e é difícil conseguir uma participação em massa (Maria Clara).

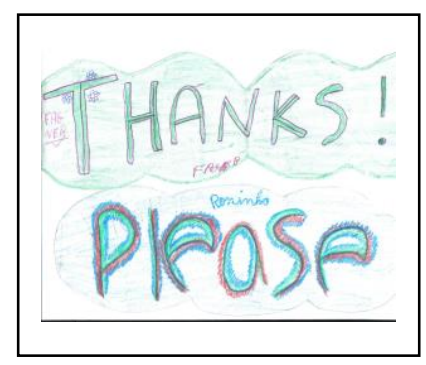

Figura 1 - Atividade feita pelos alunos

Conforme recortes expostos acima, parece haver evidências de que essa prática surtiu efeito positivo porque fez sentido para os alunos. De acordo com Williams (2001, p.33), um ponto crucial que deve ser mencionado em relação ao foco na forma é que apesar de haver um foco breve ou simultâneo em certos aspectos (como pronúncia, morfologia, sintaxe, entre outros), o foco prioritário é dado no processamento de significado no ato comunicativo em sala de aula. Os alunos da professora Maria Clara lançam mão dessas expressões com um objetivo claro: comunicar-se na língua inglesa, utilizando frases nessa língua que decodificam significados simples do dia-a-dia e que auxiliam no ato comunicativo que se desenrola (ou deveria se desenrolar) nos limites da sala de aula. Essas expressões emergem de uma necessidade de se compreender e de ser compreendido em dizeres básicos na língua inglesa, sua utilização torna-se, como isso, significativa. O resultado disso é uma aprendizagem contextualizada, e os aprendizes passam a recorrer a essa linguagem comunicativa mesmo fora da sala de aula, como pode ser percebido por meio do seguinte excerto: “... a partir deste dia a maioria dos alunos que encontravam comigo sempre falava alguma expressão em inglês..." (Maria Clara). 
Diante do resultado e das impressões e discussões decorrentes da primeira aula observada - alunos apáticos, indiferentes, desinteressados durante a aula, um novo plano de aula foi proposto pela professora e discutido com o grupo. Observando a nova proposta, tem-se o seguinte: Maria Clara inicia a aula, cumprimentando seus alunos em inglês, eles respondem e, em seguida, ela faz uma revisão de sentenças/expressões em inglês aprendidas na aula anterior, mas por meio de exemplos advindos da sala de aula: "pisei no pé do Carlos então o que posso dizer a ele..." e eles respondem em inglês; a professora pergunta então a alguns alunos: "I am talking to you now, and you, What are you doing?" e após observar seus gestos os alunos formulavam as respostas (Maria Clara também os ajudava, falando alguns verbos). A professora pede, então, que os alunos se sentem em duplas; distribui fotos (uma foto a cada aluno) e os orienta a, primeiramente, observar o que as personagens de suas fotos estavam fazendo (anexo2: plano), e, em seguida, a perguntar uns aos outros o que as personagens dos colegas estavam fazendo.

Detalhando a atividade: cada aluno recebeu uma foto diferente retirada de revistas. A professora solicitou que os alunos observassem sua figura e a ação que seu personagem desempenhava. Após essa observação, a professora pegou uma figura, e perguntou: "what are they doing"?, e enfatiza a resposta: "THEY are readING a book". Pegou em seguida outra foto e incentivou que os alunos formulassem, juntos, a pergunta correta: "what are they doing?" , assim como a resposta: "they are dancing". A professora ofereceu, ainda, exemplos com figuras que utilizam a forma singular. A partir daí, cada aluno é levado a perguntar ao colega sobre sua figura. De acordo com o que tinha em sua figura, ora perguntavam "What are they doing?", ora "what is he/she doing?". Os alunos compreendiam o modo como a pergunta devia ser formulada, processando, por isso, a aprendizagem. Entendiam, também, o modo de responder, efetivando, ainda que de forma limitada (perguntas e respostas), uma comunicação significativa uns com os outros.

O tópico focado nessa aula foi o mesmo da primeira aula (present continuous tense), mas a reação dos alunos foi outra, uma vez que, agora, participavam efetivamente. Isso aconteceu porque os alunos precisavam da forma em foco para se comunicarem; para explicar para o colega a ação desenvolvida pelos personagens de sua figura, e isso fazia sentido.

Os alunos trabalharam primeiramente de forma oral, depois colaram suas figuras e escreveram perguntas e respostas (Figura 2). 


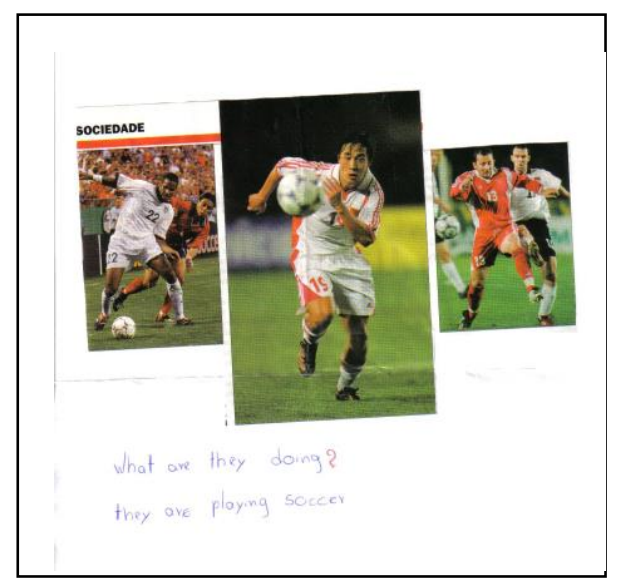

Figura 2 - Atividade feita pelos alunos

$\mathrm{Na}$ atividade proposta pela professora, os alunos em pares e com a professora, estabelecem relação entre o insumo recebido e a produção (output) resultante, promovendo a comunicação e a aprendizagem. Conforme pode ser apontado no excerto de diário abaixo:

... neste momento houve grande participação e todos sem exceção produziram perguntas e respostas. Este momento foi muito gratificante para mim e também para os alunos porque era nítida a felicidade de construir frases e poder (falar) expressá-las. ... A aula foi muito produtiva, senti a interação dos alunos com a L. Inglesa ... (Maria Clara).

Na referida aula, a professora administra a instrução, como já foi discutido, direcionando a atenção dos alunos para o uso da língua para fins comunicativos, a partir de um contexto e não para uma análise isolada de estruturas linguísticas. De acordo com Gontijo (2004, p. 107): "para que a aprendizagem seja bem-sucedida, é preciso chamar a atenção para o item a ser aprendido e usar tarefas em que se crie a necessidade de uso desse item". Em nenhum momento, a professora nomeia a estrutura gramatical aos alunos. Estes, apesar daquela primeira aula aqui apontada, não retomam nada do que foi visto outrora. O que nos leva a inferir que aquela forma estrutural (personal pronouns + verb to be + main verb + (NG -), não se mostrou eficiente para a aprendizagem. Esse fato foi também percebido pela professora, conforme trecho abaixo:

... Após a aula comentei com a $X$ sobre a primeira aula que eu ministrei sobre present continuous, cheguei à conclusão que ela não foi significativa para os alunos, pois as estruturas estudadas naquele dia, não eram lembradas durante o speaking nem mesmo da writing... (Maria Clara). 
$\mathrm{Na}$ aula seguinte, no entanto, a preocupação estava centrada no processamento efetivo do mesmo conteúdo visto na aula anterior. O plano privilegiava, ainda, a utilização do foco na forma para o ensino do present continuous tense. Acreditamos que a repetição de dadas estruturas, trabalhadas de forma contextualizada e significativa, favorece o desenvolvimento do processo de aprendizagem do aluno. Assim, a professora apresenta cartões com figuras aos alunos, perguntando: "Is she Painting? Are they playing soccer?" e os alunos respondiam as formas curtas "yes, he is." "No, they aren't" etc. Maria Clara divide, então, a turma em pares, e distribui 03 cartões a cada aluno, explicando que eles deveriam observar as figuras por três minutos e tirar as dúvidas em relação ao vocabulário e à pronúncia de uns com os outros, requisitando sua ajuda quando fosse necessário. Cada aluno de cada dupla escolheu, então, três cartões, e após os minutos determinados não os mostrou mais ao colega. Os desenhos selecionados para os cartões foram escolhidos pela professora com o objetivo de criar a necessidade de usar o present continuous tense. 0 aluno perguntava, então, ao colega: he, she, it ...? e o parceiro responderia. Depois, os alunos tinham que se recordar das figuras e formular a sentença: Is she drinking water?; Is he singing? etc., e o colega deveria responder e, assim, estabelecia-se a comunicação uns com os outros. A professora procurou utilizar o mesmo léxico da aula anterior, acrescentando apenas algumas palavras novas.

Como resultado dessa instrução, pode ser apontada a participação dos alunos e a tentativa de executar o que havia sido proposto. Houve, contudo, algum ruído, já que um queria falar mais alto que o outro, ou ver a figura novamente. Uns recorreram ao uso do português quando a palavra em inglês Ihes faltava como, por exemplo, "He is assistindo TV", mas nesse caso, algumas vezes o colega corrigia, outras vezes a própria professora o fazia. Ao final da atividade, cada aluno mostrou suas figuras, falou suas sentenças para os demais e, em seguida, escreveram suas sentenças no caderno. Observando a fala da professora em entrevista, temos o seguinte:

\footnotetext{
$P:$... o ensino da gramática/ então é assim/ no momento eu falava assim/ será que eu vou ter que mudar/ não vou dar gramática mais/ como que vai ser/ e acabou assim/ é/ teve a gramática/ ai nós trabalhamos o present continuous/ e/ ele é importante pra aquelas estruturas/ né?/ que os meninos desenvolveram/ mas só que foi de uma maneira/ assim/ bem mais agradável/ né?/ e eles tão/ eu sinto assim/ que/ eles tão mais empolgados/ até fiz um journal falando isso/ que/ eles gostam/ agora da aula/ porque parece que eles participam e tão perdendo a vergonha de falar/
} 
Desse modo, as escolhas tomadas na sala de aula pela professora Maria Clara são, em primeira instância, orientadas por suas representações sobre o ensino e a aprendizagem de LE. Por outro lado, a descoberta e a investigação dessas representações frente às possibilidades de um redirecionamento de seu fazer pedagógico pode guiá-lo à construção de uma instrução formal cujo princípio fundamental é a comunicação e aquilo que faça sentido para os alunos e lhes possibilite a aprendizagem de uma LE.

Maria Clara prossegue em sua investigação acerca das possibilidades para um fazer mais significativo. Respeitando, contudo, o limite espaço-temporal que abriga este trabalho, encerramos aqui a discussão das atividades desenvolvidas para a transformação da prática pedagógica de Maria Clara e, consequentemente, para o desenvolvimento efetivo da aprendizagem de seus alunos.

\section{Uso do foco na forma para um ensino significativo: palavras finais}

Discorrendo sobre a diferença desse aspecto da instrução formal com o foco nas formas, procuramos definir algumas de suas principais divergências, mostrando onde a prática da professora Maria Clara estava localizada e sua trajetória rumo a uma prática mais contextualizada.

A abordagem do foco na forma proporcionou aos alunos um ensino significativo, capaz de produzir efeitos sobre o modo como eles enxergavam a língua inglesa. Essa abordagem ofereceu, assim, uma necessidade e justificativa para aprender, na medida em que mobilizou os alunos a participarem da aula de forma mais efetiva.

Os rumos que essa descoberta tomará, daqui por diante, não nos seria possível inferir, mas ficou muito evidenciado que foi possível atingir o interesse e a participação dos alunos, resultando em uma aula muito mais leve, mais significativa, mais dinâmica. Afirmamos, por fim, que uma outra possibilidade para aquilo que era habitual foi explorada e avaliada, fomentando um fazer focado nas possibilidades de uma instrução significativa. Maria Clara passou a se enxergar em sua prática, vislumbrando, nessa dinâmica, modos de transformar aquilo que poderia ser transformado.

Acreditamos e defendemos a busca por um ensino que mobilize os sujeitos dessa relação, isto é, educador e educando, continuamente impulsionados a experimentar o conhecimento de si e do processo como um todo, desejando, por fim, ir além, redescobrindo uma forma nova para aquilo que se revela insuficiente, ineficiente. 


\section{Referências}

ALMEIDA FILHO, J. C. P. de. Linguística aplicada - ensino de Línguas e Comunicação.

Campinas, SP: Pontes Editores e ArteLíngua, 2005.

ALMEIDA FILHO, J.C.P. Dimensões comunicativas no ensino de línguas. Campinas: Pontes, 1993.

CORACINI, M. J. F. A celebração do outro. In: . Identidade e Discurso. Campinas:

Argos Ed. Unicamp, 2003. p. 197-221.

DUTRA, D. P. A metalinguagem no sistema pedagógico do professor. In: ; MELLO, $\mathrm{H}$.

(Orgs.) A Gramática e o Vocabulário no Ensino de Inglês: novas perspectivas. Belo

Horizonte: Faculdade de Letras, UFMG, 2004.

DUTRA, P.; MELLO, H. Os caminhos do ensino de gramática em línguas estrangeiras. In.: (Orgs.) A Gramática e o Vocabulário no Ensino de Inglês: novas perspectivas. Belo

Horizonte: Faculdade de Letras, UFMG, 2004.

MELLO, H.; DUTRA, D. P. The teaching of English aspectual categories to Brazilian Portuguese speakers: a Cognitive Grammar-based approach. In: LAUD, 2000, Essen. Series B: Applied and Interdisciplinary Papers. Essen : LAUD 2000, 2000. p. 1-8.

ELLIS, N. Memory for language. In: ROBINSON, P. Cognition and second language instruction. Cambridge: Cambridge, 2001. p. 33-68.

ELLIS, R. Formal Instruction and Second Language Acquisition. The study of second language acquisition. Oxford: Oxford, 1994. (Introdução e Capítulo 14).

GONTIJO, E. A abordagem foco na forma na aquisição de vocabulário. In: DUTRA, D. P.; MELLO, H. (Eds.). A Gramática e o Vocabulário no Ensino de Inglês: novas perspectivas. Belo Horizonte: Faculdade de Letras, UFMG, 2004. p. 103-130.

LARSEN-FREEMAN, D.; LONG, M. H. An introduction to Second Language Acquisition Research. New York: Longman, 1991. p. 12-51.

LONG, M.; ROBINSON, P. Focus on form: Theory, research and practice. In: DOUGHTY, K.; WILLIAMS, J. Focus on form in classroom second language acquisition. Cambridge: Cambridge, 1998. p. 15-41. 
MATEUS, E. T. Educação contemporânea e o desafio da formação continuada. In: GIMENEZ, T. (Org.) Trajetórias na formação de professores de línguas. Londrina: Editora UEL, 2002. p. 3-14.

MELLO, H.; DUTRA, D. P. The teaching of English aspectual categories to Brazilian Portuguese speakers: a Cognitive Grammar-based approach. In: LAUD, 2000, Essen. Series B: Applied and Interdisciplinary Papers. Essen : LAUD 2000, 2000. p. 1-8.

NUNAN, D. Research Methods in Language Teaching. Cambridge: Cambridge University Press, 1992.

ORLANDI, E.P. Análise de discurso: princípios e procedimento. Campinas: Pontes, 1999.

PAIVA, V. L. M. O.; FIGUEIREDO, F.Q. O ensino significativo de gramática em aulas de língua inglesa. In: PAIVA, V.L.M.O. (Org.). Práticas de ensino e aprendizagem de inglês com foco na autonomia. Belo Horizonte: Faculdade de Letras da UFMG, 2005. p. 173-188.

PÊCHEUX, M. Semântica e Discurso Uma Crítica à Afirmação do Óbvio. Campinas: Ed. Unicamp, 1995.

PÊCHEUX, M. FUCHS, C. A propósito da análise automática do discurso: atualização e perspectivas. In: GADET, F.; HAK, T. (Orgs.) Por uma análise automática do discurso: uma introdução à obra de Michel Pêcheux. 3. ed. Campinas: Editora da Unicamp, 1997. p 163246.

SAGOR, R. How to conduct collaborative action research. Alexandra: Virginia ASCD, 1993. SCHIMIDT, R. Attention. In: ROBINSON, P. Cognition and second language instruction. Cambridge: Cambridge, 2001. p. 3-32.

SWAIN, M. Communicative competence: some roles of comprehensible input and comprehensible output in its development. In: Gass, S. \& Madden, C. (Eds.). Input in second language acquisition. Rowley: Newbury House, 1985. p. 235-253.

TELLES, J. “É pesquisa, é? Ah, não quero, não, bem!" Sobre pesquisa acadêmica e sua relação com a prática do professor de línguas. Linguagem e Ensino. Pelotas, V. 5, n. 2, p 91-11, julho 2002. 
WILLIAMS, J. Focus on form: research and its implication. Revista Brasileira de Linguística Aplicada, Belo Horizonte, v. 1, n. 1, p. 31-52, out. 2001.

Enviado em Março/2012

Aprovado em Março/2013 


\section{ANEXO 1}

Perguntas que orientaram a entrevista:

1. O que é ser professor de inglês para você?

2. O que significa ensinar para você?

3. O que precisa ser ensinado?

4. O que os alunos querem aprender?

5. Como você define ensino de gramática na sala de aula?

6. Como você ensina gramática em suas aulas de inglês? 


\section{ANEXO 2}

Plano de Aula da Professora Maria Clara em sua primeira aula observada:

$$
\begin{aligned}
& a^{0} \text { semestre. } \\
& \text { Lingua Inglesa }
\end{aligned}
$$

Months: August / September/October/November

\section{December.}

\section{Salas 2 \& 5}

* Present Continunus

* 's genitive case I whose $*$ / whquestions $\rightarrow$ next class

* Some lany

* Prepositions

Vocabulary

Places/ cooking

house/ Seasons

15. 08.05

Sala 2.

Topico: What are Yjou doing?

- Rever os subject pronouns.

- ixpor as piguras no quadro.

- Observagão das imagerr

$-$

verls

to date to sleep
to Wash to cale
to read to toirs

to play

Explicar sobre o acréscimo do - ing

Estruturia do present continuous of

webject + verb to be + verb. (ing)
What are they doing? They are drinsaing ajuice 
Explicar formad afuimativas/inegativa/ inturugativa.

Exercises

Wrabel - read - book

1. Label is reading a bootz.

2. Is Isabel reading a books?

3. Saciel isn't readiring a book.

a) Brurne - Walch tv

b) you - call me

c) they - play football

d) You - take piarne lessors

e) she study

i) You-listen to me

j) andrew. Sleep

ki) Gou - come vlitin me

l) Alice. proint rrold

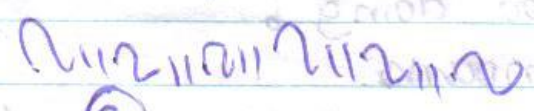

sala (6)

2o sumistre

last continuous ternse *

loat terva

prepositions

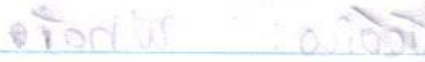

many | few / much / little

sume / any

can / must / should.

13-08-05

Prepositions

Resourches: Transparênciá.

Text: My home. 